\title{
The occurrence and potential ecological risk assessment of bauxite mine-impacted water and sediments in Kuantan, Pahang, Malaysia
}

\begin{abstract}
Recent bauxite mining activities in the vicinity of Kuantan, Pahang, have been associated with apparent environmental quality degradation and have raised environmental concerns among the public. This study was carried out to evaluate the overall ecological impacts on water and sediment quality from the bauxite mining activities. Water and sediment samples were collected at seven sampling locations within the bauxite mining areas between June and December 2015. The water samples were analyzed for water quality index (WQI) and distribution of major and trace element geochemistry. Sediment samples were evaluated based on geochemical indices, i.e., the enrichment factor (EF) and geoaccumulation index (Igeo). Potential ecological risk index was estimated to assess the degree to which sediments of the mine-impacted areas have been contaminated with heavy metals. The results showed that WQIs of some locations were classified as slightly polluted and contained metal contents exceeding the recommended guideline values. The EFs indicated minimal to moderate enrichment of metals $(\mathrm{Pb}, \mathrm{Cu}, \mathrm{Zn}, \mathrm{Mn}, \mathrm{As}, \mathrm{Cd}, \mathrm{Cr}, \mathrm{Ni}, \mathrm{Co}$, and $\mathrm{Sr})$ in the sediments. Igeo showed slightly to partially polluted sediments with respect to As at some locations. The potential ecological risk index (RI) showed that As posed the highest potential ecological risk with RI of $52.35 \mathrm{i} 60.92$ at two locations, while other locations indicated low risk. The findings from this study have demonstrated the impact of recent bauxite mining activities, which might be of importance to the local communities and relevant authorities to initiate immediate rehabilitation phase of the impacted area.
\end{abstract}

Keyword: Bauxite; Ecological risk index; Geochemical index; Heavy metal; Mine water; Sediment 